\title{
Trade-offs in Parasitology, Evolution and Behavior
}

\author{
M. Zuk, M.J. Bryant, G.R. Kolluru and V. Mirmovitch
}

Most animal pare' its find caring for offspring to be costly, whether in terms of increased vigilance against predators or higher grocery bills. Most parasitologists know that defense against pathogens is costly as well, requiring elaborate physiological and biochemical mechanisms to recognize and destroy the invader: In both cases, the parent or host can be seen as making a trade-off, allocating energy to one task, such as protection of the young or production of macrophages, at the expense of another, such as feeding oneself or devoting energy to growth rather than immune defense. Trade-offs in life history traits are much studied in evolutionary biology and ecology; examples include the choice between early maturation and growth ${ }^{12}$, the production of a few large offspring vs many smaller ones 1.2 , or the investment in reproducing this year rather than saving some resoures for a later season 1 . Only recently, however, has the notion of a life history trade-off been linked to parasite

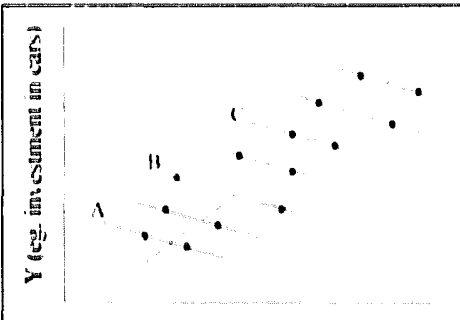

$X$ (eg. investment in housing)

Fig. I. The car-house paradox. For a given income, there is a trade-off between the potential investment in cars and that in a house, shown by the negative slope of the solid lines. For example, a person with a low income (A) can spend relatively little on both cars and houses. At higher incomes (B and $C$ ), more money can be spent in total, but the trade-off still exists within each individual. Examination of the expenditures across individuals, however, fails to show this trade-off, as illustrated by the dashed line with the positive slope. In the case of the great tits, each parent may be of int insically different quality, with a trade-off between investment in parental effort and in parasite defense within individuals, but one that is not apparent among individuals unless manipulation experiments are performed. defense, with the suggestion by Richner et $a .^{3}$ that parasite infection may be influenced by the allocation of energy to parental behavior in free-living animals.

Using the great tit (Porus major), a well-studied European songbird. Richner and colleagues manipulated brood sizes by moving newly hatched chicks from one nest to another. They thus altered the amount of work required to keep the nestlings fed. In enlarged broods, male parents, but not females, increased their rates of provisioning. This elevated effort had an intriguing apparent cost: the overworked males also showed more than double the rate of infection with malaria (Plasmodium SPF) when compared with birds with reduced or unmanipulated broods, as evidenced by exarnination of blood smears taken from all the birds during the breeding season. This result was surprising, because it contradicts the often-obseived finding that heavily parasitized individ. uals are those with lower, not higher, reproductive success" is. The mechanism behind the association between parental effort and parasitemia is unclear; are the miles who expend gieater effort simply exposing themselves to the dis. case vectors more often than other males. or do the increased effort and stress of the parent decrease the eneigy aveilable for immune defense?

Both the expected direction of the correlation between parasite burden and fitness and the nature of the mechanism behind the link between parasites and behavior are topics of current interest in ecology and evolution, with numerous implications for parasitology. In each case, a more-thorough understanding of parasite biology could potentially help untangle presentiy elusive connections.

The notion that individual differences in parasite resistance could influence the evolution of behavior has appeared in several contexts. Most recently, Folstad and Karter ${ }^{9}$ suggested that females choosing to mate with males exhibiting well-developed secondary sexual ornaments, such as the comb on a rooster, may in the ultimate evolutionary sense be choosing a mate with genes that offset the immunosuppression that often accompanies the production of testosterone-dependent traits. The offspring then inherit not only the attractiveness of their father, but also his ability to resist pathogens while maintaining elaborate ornaments. Wedekind and Folstad ${ }^{10}$ speculated that high-quality males may be better able to allocate energy to ornament production as well as to parasite defense, suggesting the same kind of trade-off as described above. The energetics of parasite resistance are virtually unknown. however, and t may be premature to suggest a simple additive model for energy use in physiological processes. Although a hardful of studies have fourid $a$ negative relationship between ornamentation and some aspect of immure respunse ${ }^{11.12}$ (F. Skarstein, Cand. Sci. Thesis, University of Tromso, Norwiy, 1394), research on the mechanism(s) behind such a lirik is sorely needed. Furthermore, the greater attractiveness of males with poorer immune responses in these studies presents the opposite relationship between parasite defense and fitness shown by Richner et al., underscoring the need for an understanding of the actual costs of resistance. One set of studies indicates that the price of omamentation and preference by females may be reduced immunocompetence, while the Richrier et al. work suggests that increased investment in parenting could exert a cost in teims of parasite defense.

The use of manipulation experiments, rather than reliance on correlations between immune response and feeding rates in the field. also illustrates how such experiments can circumvent spurious correlations in life history traits. a pitfall sometimes called the car-house paradox 3 . Given limited amounts of money for any individual, one might expect that any funds put into a person's house would restrict the amount left for spending on a car, and thus a negative correlation between house and car allocation should arise, similar to the trade-off between, say, number and size of offspring. In reality, of course, one sees the exact opposite: people with expensive cars tend to have costly real estate, arid vice versa. The paradox arises berause individuals differ in the amount cf resources they start off with, as showr in Fig. 1. Similarly, without manipulating brood sizes, it would be impossible to distinguish between some 
adults being intrinsically poorer at combining parental care with parasite defense from the cause-and-effect relationship proposed by Richner et al. ${ }^{3}$ At the same time, performing the experiment in the field allows evaluation of such trade-offs in Nature, rather than under laboratory conditions with unkriown relevance to the real world.

The role of trade-offs in parasitology is an unexplored and potentially exciting area of research. Although researchers are increasingly studying the effects of parasites in natural populations $^{14}$, few have examined the mechanisms behind relationships such as the one uncovered by Richner et al. In addition, the work on the great tits suggests that the epidemiology of parasites in Nature may be more complex than previously supposed, and mav depend partly upon life history traits such as residual reproductive value (the amount of future reproduction left in an individual's life). An older individual with fewer reproductive episodes remaining in life might be expecteci to devote less effort to parasite defense than a younger one, for examplet. The time of year may also play a part in disease dynamics, with animals showing different patterns of infection during the breeding season than at other times. The sex difference seen in the great tits in the amount of effort in resporise to brood increases as well as in parasite burdens likevvise warrants further study. Finally, parasite virulence itself may be seen as a tradeoff, with greater transmission being balanced against the degree of virulence of a pathogen ${ }^{15.16}$. All of these areas provide questions for fruitful collaborations between ecology, evolution, behavior and parasitology.

\section{Acknowledgements}

Kurt A. Mcikean provided helpful discussion. $M$. Zuk's research is funded by the National Science Foundation (USA).

\section{References}

I Roff. D.A. (1992) The Evolution of Life Historles: Tr eory and Anolysis. Chapman \& Hall
2 Steains. S.C. (1992) The Evolution of Life Hisione5, Jxiond

3 Richner, H. et al. (1995) Proc. Notl Acod. Sci. USA 92. $1192: 194$

4 Møller. A.P. (1990) Evolution 44.771-784

5 Moller. A.P. (1791) Anim. Behov. 41, 723-730

6 Moller, A.P. (1991) Functiond Ecol 5. 351359

7 Clayton, D.H. (1991) Parusitology Todoy 7. 329.334

8 Zuk. M. (1992) Adv. Study Behov. 21. 39-68

9 Folstad. I. and Karter. A.J. (1992) Am. Nat. 139. $603-622$

10 Wedekind. C. and Folsiad. I. (1994) Am. Nat. 143. 936938

1 Saino. N. et al. Behav. Ecol. (ir press)

12 Zuk. M. el al. (1995) Proc. R. Soc. Loridon Ser. B 269. 205210

13 van Noordwijk. A.J. and de jong. G. (1986) Am. Nat. 128. $137 \quad 142$

14 Loye, J. and Camoll. S. (1995) Trends Ecol. Evol. 10,232235

15 Ewald. P.W. (1994) Evolution of Infectious Disecse, Oxford University Pre'ss

16 Bull. J.) (1994) Evoitution 48, 14231437

Marlene Zuk, Michoel j Bryunt. Gita Raman Kolluru and Vered Mirmovitch are at the Department of Biology. University of Californio. Riverside. CA 4.?21, USA. 